\title{
Hyperbaric oxygen preconditioning attenuates hyperglycemia enhanced hemorrhagic transformation after transient MCAO in rats
}

\author{
Yoshiteru Soejima, Robert P Ostrowski, Anatol Manaenko, Mutsumi Fujii, Jiping Tang and John H Zhang*
}

\begin{abstract}
Background: Hemorrhagic transformation $(\mathrm{HT})$ can be a devastating complication of ischemic stroke. Hyperbaric oxygen preconditioning (HBO-PC) has been shown to improve blood-brain barrier (BBB) permeability in stroke models. The purpose of this study is to examine whether HBO-PC attenuates HT after focal cerebral ischemia, and to investigate whether the mechanism of HBO-PC against HT includes up-regulation of antioxidants in hyperglycemic rats.

Methods: Male Sprague-Dawley rats (280-320 g) were divided into the following groups: sham, middle cerebral artery occlusion (MCAO) for $2 \mathrm{~h}$, and MCAO treated with HBO-PC. HBO-PC was conducted giving 100\% oxygen at $2.5 \mathrm{~atm}$ absolute (ATA), for $1 \mathrm{~h}$ at every $24 \mathrm{~h}$ interval for 5 days. At $24 \mathrm{~h}$ after the last session of HBO-PC, rats received an injection of 50\% glucose (6 ml/kg intraperitoneally) and were subjected to MCAO 15 min later. At $24 \mathrm{~h}$ after MCAO, neurological behavior tests, infarct volume, blood-brain barrier permeability, and hemoglobin content were measured to evaluate the effect of HBO-PC. Western blot analysis of nuclear factor erythroid 2-related factor 2 (Nrf2) and heme oxygenase-1 (HO-1) was evaluated at multiple time-points before and after MCAO.

Results: HBO-PC improved neurological behavior test, and reduced infarction volume, $\mathrm{HT}$ and Evans blue extravasation in the ipsilateral hemisphere at $24 \mathrm{~h}$ after MCAO. Western blot analysis failed to demonstrate upregulation of Nrf2 in HBO-PC group before and after MCAO. Paradoxically, HBO-PC decreased HO-1 expression at $24 \mathrm{~h}$ after MCAO, as compared with htMCAO group.

Conclusions: HBO-PC improved neurological deficits, infarction volume, BBB disruption, and HT after focal cerebral ischemia. However, its mechanism against focal cerebral ischemia and HT may not include activation of Nrf2 and subsequent HO-1 expression.
\end{abstract}

Keywords: Hemorrhagic transformation, MCAO, Hyperbaric oxygen preconditioning, Nuclear factor erythroid 2related factor 2 (Nrf2), Heme oxygenase-1 (HO-1)

\section{Background}

Hemorrhagic transformation (HT) of ischemic stroke contributes largely to the early mortality and poor functional recovery of affected patients. Experimental studies have shown that preischemic hyperglycemia increases the risk of bleeding into cerebral infarction area, which aggravates brain damage after reperfusion [1]. Hyperglycemia-enhanced HT may be linked to increased activity of inflammation and oxidative stress, which cause

\footnotetext{
* Correspondence: johnzhang3910@yahoo.com
Department of Physiology and Pharmacology, Loma Linda University School

* Correspondence: johnzhang3910@yahoo.com
Department of Physiology and Pharmacology, Loma Linda University School of Medicine, Loma Linda, CA, USA
}

(c) 2012 Soejima et al; licensee BioMed Central Ltd. This is an Open Access article distributed under the terms of the Creative Commons Attribution License (http://creativecommons.org/licenses/by/2.0), which permits unrestricted use, distribution, and reproduction in any medium, provided the original work is properly cited. blood-brain barrier (BBB) disruption and neuronal cell death [2]. Oxidative stress leading to ischemic cell death involves the formation of reactive oxygen species/reactive nitrogen species (ROS/RNS), which induce BBB disruption through degradation of junctional proteins composing tight junction $[3,4]$.

Nuclear factor erythroid 2-related factor 2 (Nrf2), a cap ' $n$ ' Collar transcription factor, regulates a lot of antioxidant/detoxification genes acting in synergy to remove ROS/RNS through sequential enzymatic reactions [5,6]. Under non-stressed conditions, Nrf2 interacts with Kelch-like ECH-associated protein 1 (Keap l) to form 
the Keap 1-Nrf2 complex that limits Nrf2-mediated gene expression. Upon activation, the Keap 1-Nrf2 complex is dissociated, Nrf2 translocates into the nuclei to bind antioxidant response element (ARE) and activates ARE-dependent transcription of important antioxidant and detoxification genes (Phase II genes) [5]. Phase II genes, including heme oxygenase-1 (HO-1), glutathione $\mathrm{S}$-transferases (GSTs) and $\mathrm{NAD}(\mathrm{P}) \mathrm{H}$ quinone oxidoreductase, work in synergy to constitute a pleiotropic cellular defense that scavenges ROS/RNS, detoxifies electrophiles and xenobiotics, maintain intracellular reducing potential $[7,8]$. $\mathrm{HO}-1$ is a ubiquitous and redox-sensitive inducible stress protein that degrades heme to carbon monooxide, iron and biliverdin [9]. All products of heme oxygenases exert strong antioxidant, anti-inflammatory and antiapoptotic effects.

Hyperbaric oxygen preconditioning (HBO-PC) induces tolerance against brain ischemia reperfusion injury by up-regulation of antioxidant enzymes [10], as well as ischemia tolerance in organs including the spinal cord [11], myocardium [12], and liver [13]. Recent investigation indicated that HBO-PC could induce cytoprotective effect on human microvascular endothelial cell via upregulation of Nrf2 and HO-1 [14]. The purpose of this study is to examine whether HBO-PC attenuates HT after focal cerebral ischemia, and to investigate whether the mechanism of HBO-PC against HT includes Nrf2/ HO-1 up-regulation in hyperglycemic rats.

\section{Methods}

Animal preparation and MCAO

All experiments were approved by the Institutional Animal Care and Use Committee of Loma Linda University; 96 male Sprague-Dawley rats were purchased from Harlan Laboratories (Indianapolis, IN) and randomly divided into the following groups: middle cerebral artery occlusion (MCAO) with hemorrhagic transformation (htMCAO; $\mathrm{n}=40$ ), $\mathrm{HBO}$ preconditioned htMCAO (HBO-PC; $\mathrm{n}=40$ ), and sham-operated group (sham; $\mathrm{n}$ = 16) for analysis of Evans blue extravasation and Western blot. All rats received 50\% dextrose $(6 \mathrm{ml} / \mathrm{kg})$ intraperitoneally $30 \mathrm{~min}$ before MCAO to induce acute hyperglycemia. Anesthesia was induced with ketamine and xylazine $(80 \mathrm{mg} / \mathrm{kg}$ and $10 \mathrm{mg} / \mathrm{kg}$ respectively, intraperitoneally), followed by atropine at a dose of 0.1 $\mathrm{mg} / \mathrm{kg}$ subcutaneously. During surgery and postoperative period, rectal temperature was maintained at $37.0^{\circ} \mathrm{C}$ by using a feedback-controlled heating pad.

MCAO was performed as reported previously [15]. Briefly, the right external carotid artery was isolated and coagulated. A 4-0 nylon suture with a round tip was inserted into the internal carotid artery through the external carotid artery stump and advanced to occlude the origine of MCA. The suture was removed at $2 \mathrm{~h}$ after occlusion. Blood was obtained from the tail vein for analysis of glucose level at multiple time-points.

\section{HBO-PC regimen}

Rats were pressurized in a research hyperbaric chamber (1300B; Sechrist) at $2.5 \mathrm{~atm}$ absolutes with 100\% oxygen (flow of $22 \mathrm{~L} / \mathrm{min}$ ). Compression and decompression were maintained at a rate of $5 \mathrm{psi} / \mathrm{min}$. A 1 -h $\mathrm{HBO}$ session was administered daily for 5 consecutive days; the last session was performed $24 \mathrm{~h}$ before MCAO.

\section{2,3,5-triphenyltetrazolium chloride staining and evaluation of infarction volume}

As previously reported [15], 2,3,5-triphenyltetrazolium chloride monohydrate (TTC) staining was performed to determine the infarct volume at $24 \mathrm{~h}$ after MCAO. The possible interference of brain edema with infarct volume was corrected by standard methods (whole contralateral hemisphere volume - nonischemic ipsilateral hemisphere volume) and the infarct volume was expressed as a ratio of infarct volume to the whole contralateral hemisphere [16].

\section{Spectrophotometric assay of hemoglobin}

Hemorrhagic transformation was quantified with spectrophotometric assay of brain hemoglobin content [17]. At $24 \mathrm{~h}$ after MCAO (22 h after reperfusion) or shamoperation, the animals were perfused transcardially with $0.1 \mathrm{~mol} / \mathrm{l}$ phosphate-buffered saline under deep anesthesia until the outflow fluid from the right atrium was colorless. The brain was rapidly removed and dissected into the left hemisphere and the right hemisphere.

Cerebral hemorrhage was quantified using a previously described spectrophotometric assay with some modifications [17]. A standard curve was obtained using a "virtual" model of hemorrhage. Incremental volumes of homologous blood $(0,2,4,8,16,32 \mu \mathrm{l})$ were added to the perfused brain tissue. The hemispheric brain tissue was then homogenized in distilled water followed by 30 min centrifugation $(13,000 \mathrm{~g})$. Drabkin reagent $(1.6 \mathrm{ml}$; Sigma) was added to $0.4 \mathrm{ml}$ supernatant aliquots and optical density was measured at $540 \mathrm{~nm}$ via spectrophotometer (Spectronix 3000; Milton-Roy). Hemoglobin measurements were performed and compared with the standard curve to obtain data in terms of hemorrhage volume. The total hemispheric hemoglobin content was expressed as $\mu$ l of blood per hemisphere.

\section{Measurement of evans blue dye extravasation}

The integrity of the BBB was investigated by measuring the extravasation of Evans blue in sham, htMCAO, and HBO-PC group ( $n=5$ each). Evans blue dye ( $2 \%$ in saline, $5 \mathrm{ml} / \mathrm{kg}$ ) was injected intravenously at $23 \mathrm{~h}$ after operation. One hour after Evans blue injection, the chest wall was 
opened under deep anesthesia and animals were perfused with $0.1 \mathrm{~mol} / \mathrm{l}$ phosphate-buffered saline through the left ventricle to remove the intravascular localized dye until colorless perfusion fluid was obtained from the right atrium. After decapitation, brains were removed, weighed, and homogenized in $1.0 \mathrm{ml}$ of $0.1 \mathrm{~mol} / \mathrm{l}$ phosphate-buffered saline, and centrifuged at 15,000 rpm for $30 \mathrm{~min}$. Then $0.6 \mathrm{ml}$ of the resultant supernatant was added to an equal volume of trichloroacetic acid. After overnight incubation at $4^{\circ} \mathrm{C}$ and centrifugation at $15,000 \mathrm{rpm}$ for $30 \mathrm{~min}$, the supernatant was measured at $615 \mathrm{~nm}$ for absorbance using a spectrophotometer (pectronix 3000; Milton-Roy). The tissue content of Evans blue was quantified from a linear standard curve and was expressed as micrograms per gram of brain tissue [18].

\section{Neurological scores}

At $24 \mathrm{~h}$ after $\mathrm{MCAO}$, a neurological examination was performed by a blinded investigator as previously described with modifications [19]. The scores given to each rat at the completion of the evaluation was the summation of all 7 individual test scores [20].

\section{Western blot analysis}

The animals were euthanized under general anesthesia at $24 \mathrm{~h}$ after operation ( $\mathrm{n}=6$, each group), 2 and $24 \mathrm{~h}$ after the last $\mathrm{HBO}$ session $(\mathrm{n}=5$, each). Brains were collected and protein extracts from nuclear and cytosolic fraction were obtained using a nuclear extraction kit and following the manufacturer protocol (Millipore). Equal amounts of total protein $(20 \mu \mathrm{g})$ were separated in $10 \%$ SDS-PAGE and blotted onto nitrocellulose membranes. The probing antibodies included polyclonal rabbit anti-Nrf2 antibody (1:1000; Abcam Inc), rabbit antiheme oxygenase 1 (HO-1) polyclonal antibody (1:1000; Enzo Life Sciences), goat anti-actin (1:2000; Santa Cruz), and mouse anti-histone $\mathrm{H} 1$ monoclonal antibody (1:500; Millipore Inc). Bands were detected by ECL plus Western blotting detection kit (GE Healthcare) and recorded on X-ray film (Kodak). Bands were quantified by optical density method using Image J software, and densities were expressed relative to histone $\mathrm{H} 1$ (nuclear fraction), actin (cytosolic fraction) or sham.

\section{Statistical analyses}

Data were expressed as the mean \pm SEM. Statistical differences among groups were analyzed by using one-way analysis of variance followed by the Turkey method. Comparisons between the two groups for the infarction volume, hemorrhagic volume and the neurological scores were assessed by the unpaired $t$-test, and for mortality rate by chi-square test. $P<0.05$ was considered statistically significant.

\section{Results}

\section{Blood glucose level}

The glucose levels at $2 \mathrm{~h}$ after injection in both groups were significantly higher than the baseline and high glucose level was lasted by $6 \mathrm{~h}$ after injection. HBO-PC had no effects on the blood glucose level (Figure 1).

\section{HBO-PC attenuated the outcomes of hyperglycemia induced $\mathrm{HT}$ at $\mathbf{2 4} \mathrm{h}$ after MCAO}

To examine whether HBO-PC exerts a beneficial effect on HT after focal ischemia, neurological scores, infarction volume and hemorrhagic volume were evaluated in htMCAO and HBO-PC group. $\mathrm{HBO}$ preconditioned animals showed statistically better neurological function as compared with those of htMCAO group (7.00 \pm 1.55 versus $12.58 \pm 1.36, P<0.01$; Figure 2$)$. HBO-PC significantly reduced the infarction volume on TTC staining at $24 \mathrm{~h}$ after MCAO $(0.260 \pm 0.017$ versus $0.126 \pm 0.031, P$ $<0.01$; Figure 3A, B). Spectrophotometric measurement of brain hemoglobin showed that hemoglobin contents of $\mathrm{HBO}$ preconditioned animals were significantly lower than those of htMCAO group $(10.37 \pm 1.69$ versus $15.17 \pm 0.76 \mu \mathrm{L} /$ hemisphere, $P<0.05$; Figure $3 \mathrm{C}$ ).

Evans blue extravasation with righ hemisphere of htMCAO animals was significantly increased as compared with those of sham operated rats $(4.52 \pm 0.83$ versus $1.99 \pm 0.42 \mu \mathrm{g} / \mathrm{g}, P<0.05)$. HBO-PC significantly reduced the extravasation of Evans blue as compared with those of htMCAO group (4.52 \pm 0.83 versus $2.16 \pm$ $0.47 \mu \mathrm{g} / \mathrm{g}, P<0.05$; Figure 4).

However HBO-PC failed to improve the mortality rate as compared with htMCAO group (32.5\% versus $37.5 \%$

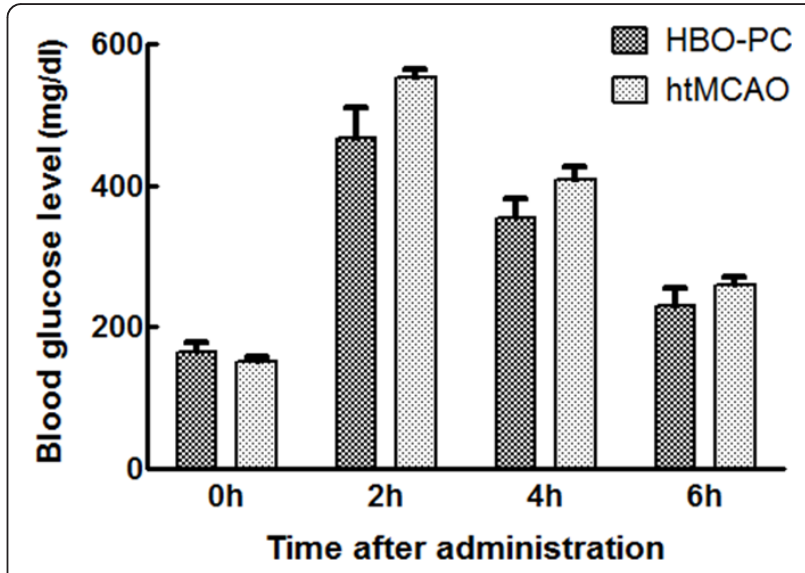

Figure 1 Hyperbarc preconditioning had no effect on blood glcose levels at 4 time-points. Blood was obtained from the tail vein for analysis of blood glcose before, 2 h, 4 h, and $6 \mathrm{~h}$ after administration of dextrose. There were not significant differences in the time course of blood glucose levels between HBO-PC group and htMCAO group. 


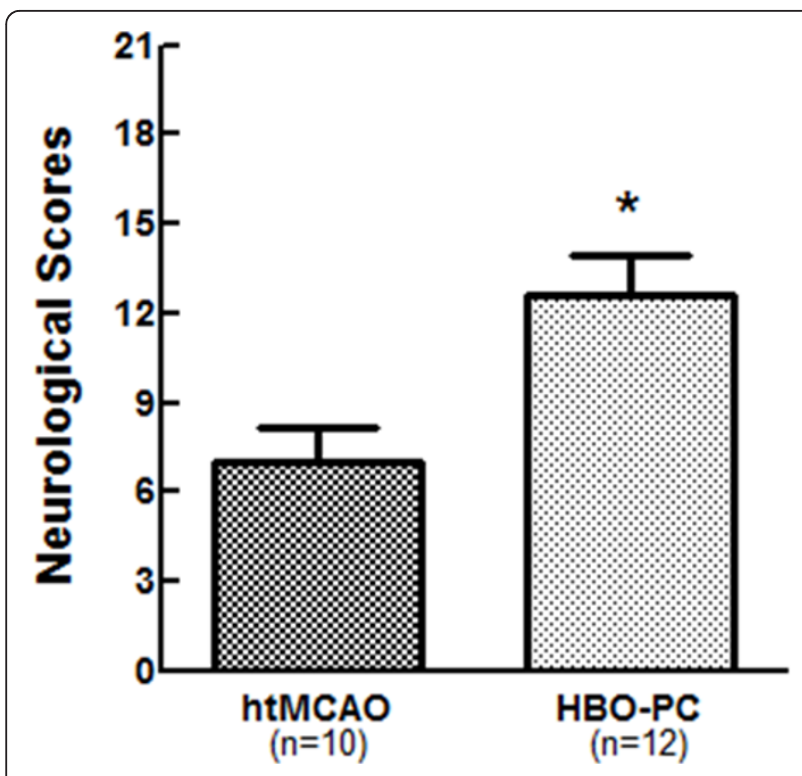

Figure 2 HBO preconditioning significantly improved neurological outcome. Modified Garcia score was used. The minimum neurological score (most severe) was 3 , and the maximum was 21 . $\mathrm{HBO}$ preconditioning significantly improved the postischemic neurological deficit at $24 \mathrm{~h}$ after MCAO.

in htMCAO group, $P>0.05$, chi-square test). No animal died in the sham group.

\section{HBO-PC failed to increase Nrf2 activity and HO-1 expression}

Western blot analysis showed that $\mathrm{HBO}-\mathrm{PC}$ had no effect on Nrf2 regulation. No change was found in the protein expression of Nrf2 in both fractions at 2 or 24 $h$ after the last session of $\mathrm{HBO}$, without subsequent MCAO (Figure 5). Furthermore, there was no significant difference in Nrf2 expression of both fractions at $24 \mathrm{~h}$ after MCAO as compared with htMCAO group (Figure 6). Result also shows that no change was found in time-course of HO-1 expression (Figure 5C). However, It is notable that HBO-PC decreased HO-1 at 24 $\mathrm{h}$ after MCAO as compared with htMCAO group (Figure $6 \mathrm{C})$.

\section{Discussion}

In this study, we investigated the effect of $\mathrm{HBO}-\mathrm{PC}$ on $\mathrm{HT}$ after transient MCAO and demonstrated that HBO$\mathrm{PC}$ reduced neurological deficit, infarction volume, BBB permeability and HT at $24 \mathrm{~h}$ after ischemia. However, no change was found in time-course of Nrf2 in nuclear fraction and HO-1 in cytosolic fraction after repeated $\mathrm{HBO}$ exposure, and Nrf2 in nuclear fraction was not upregulated by $\mathrm{HBO}-\mathrm{PC}$ at $24 \mathrm{~h}$ after MCAO.
Paradoxically, HBO-PC reduced the protein expression of HO-1 as compared to htMCAO group.

It has been previously suggested that exposure to nonlethal stress can induce protection against subsequent exposure to lethal or more severe stress of a different kind, which is known as cross-tolerance [21]. HBO-PC has been demonstrated to induce cross-tolerance against global cerebral ischemia [22] and focal cerebral ischemia [23]. Under the condition of critical oxidative stress like reperfusion injury, effects of $\mathrm{HBO}-\mathrm{PC}$ have been attributed not only to reducing ROS/RNS but also to increase of antioxidants which are induced by non-lethal oxidative stress.

Microarray analysis showed that gene expression of Nrf2 and HO-1 was immediately upregulated after $\mathrm{HBO}$ administration in human microvascular endothelial cells [14]. In in vivo models, $\mathrm{HBO}$ has been shown to induce HO-1 overexpression in the lung [24]. HBO-PC could induce tolerance against ischemia-reperfusion injury by upregulation of HO-1 expression and activity in liver [25] and kidney [26]. Our data did not confirm these findings in the brain of glucose enhanced HT model.

It has been demonstrated that repeated $\mathrm{HBO}$ reduced superoxide dismutase and catalase while glutathione peroxidase was up-regulated as compared to single exposure of $\mathrm{HBO}$ in blood plasma of patients [27] and the liver of rats [28]. Hence, there is possibility that certain antioxidants may be reduced by repeated exposure of $\mathrm{HBO}$ as compared with single exposure. Nrf2 is considered to be activated by ROS/RNS as a non-lethal stress caused by $\mathrm{HBO}$ exposure. As a result, repeated preconditioning with $\mathrm{HBO}$ down-regulates Nrf2 activation and its downstream effector $\mathrm{HO}-1$ after ischmic insult. On the other hand, several studies measured antioxidants as potential indirect markers of oxidative stress taking place in the brain with stroke [29]. Hemorrhagic transformation and infarction volume of HBO preconditioned group was significantly reduced in this current study, which indicates $\mathrm{HO}-1$ was up-regulated in proportion to the degree of hemorrhagic transformation and infarction. In any case, activated Nrf2/ARE pathway and subsequent HO-1 up-regulation could not be regarded as a cause of reducing $\mathrm{HT}$ after repeated $\mathrm{HBO}$ exposure in focal ischemia rats.

In this study, hemoglobin leakage in the brain of $\mathrm{HBO}-\mathrm{PC}$ group was approximately $32 \%$ less than in htMCAO group, whereas infarction volume was approximately $52 \%$ less. These results indicate that attenuation of HT after HBO-PC can be accountable for reduction in infarction volume. However, Evans blue extravasation in $\mathrm{HBO}-\mathrm{PC}$ was significantly reduced and approximating to those of the sham group at $24 \mathrm{~h}$ after 

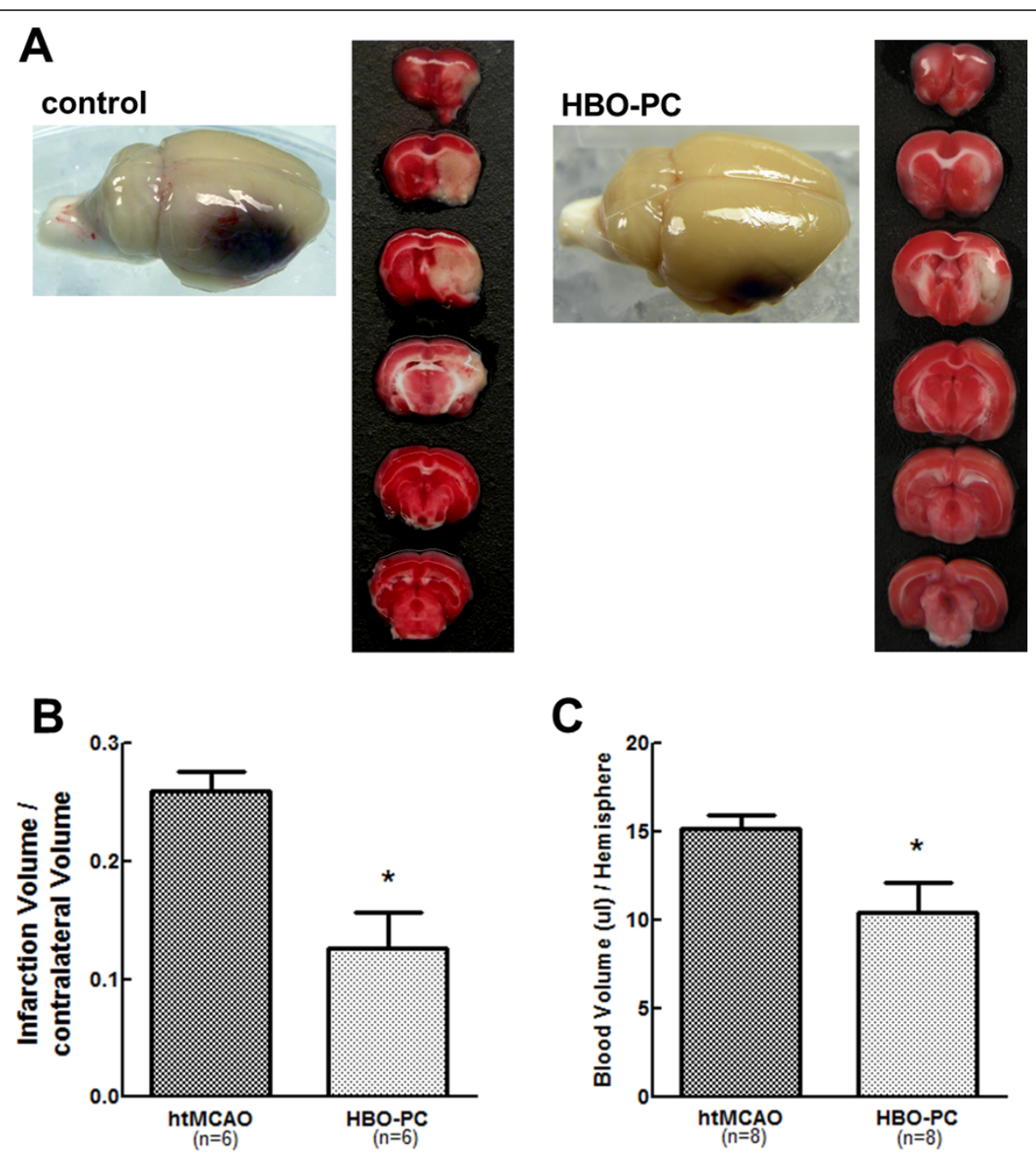

Figure 3 HBO preconditioning significantly reduced infarction volume and hemorrhage volume. (A) Representative whole brains and brain slices with 2,3,5-triphenyltetrazolium chloride staining of each groups were demonstrated. HBO-PC reduced infarction volume and attenuated hemorrhagic transformation. (B) Bar graphs showing average infarct size calculated in six slices. HBO-PC significantly reduced infarct volume at $24 \mathrm{~h}$ after reperfusion compared to htMCAO group. (C) Hemorrhage volume was significantly reduced with $\mathrm{HBO}-\mathrm{PC}$. ${ }^{*} P>0.05$ vs. hIMCAO.

MCAO. This result suggested that HBO-PC is expected to reduce $\mathrm{BBB}$ permeability more effectively if observation is undertaken over an extended period. Previous reports demonstrated that HBO-PC suppressed matrix metalloproteinase (MMP) 9 activity after global ischemia [30] and focal ischemia in brain [31]. In the context of HT after cerebral ischemia, MMPs may degrade extracellular matrix and vascular basal lamina, weaken vessels, and predispose them to leakage and rupture. These reports indicate that HBO-PC can reduce HT not only due to the reduction of infarction volume but amelioration of $\mathrm{BBB}$ disruption.

HBO-PC did not reduce the mortality rate comapred to htMCAO group despite improvement in neurobehavior tests and $\mathrm{HT}$. It is possible that HBO-PC did not improve systemic complications due to hyperglycemia and MCAO that contributed to the high mortality rates. Systemic complications such as extracellular acidosis have been reported to occur after transient MCAO in hyperglycemic rats [32]. Further study will be needed to investigate the complications which are not directly related to the brain damage but may cause high mortality rates.

HBO-PC has been suggested to reduce oxidative stress, inflammation, and apoptosis in ischemia-reperfusion injury. The result of this study indicates that there are some other mechanisms which contribute to attenuate HT after glucose enhanced ischemia-reperfusion injury in brain. To our knowledge, this is the first investigation that $\mathrm{HBO}-\mathrm{PC}$ can reduce $\mathrm{HT}$ after ischemia. 


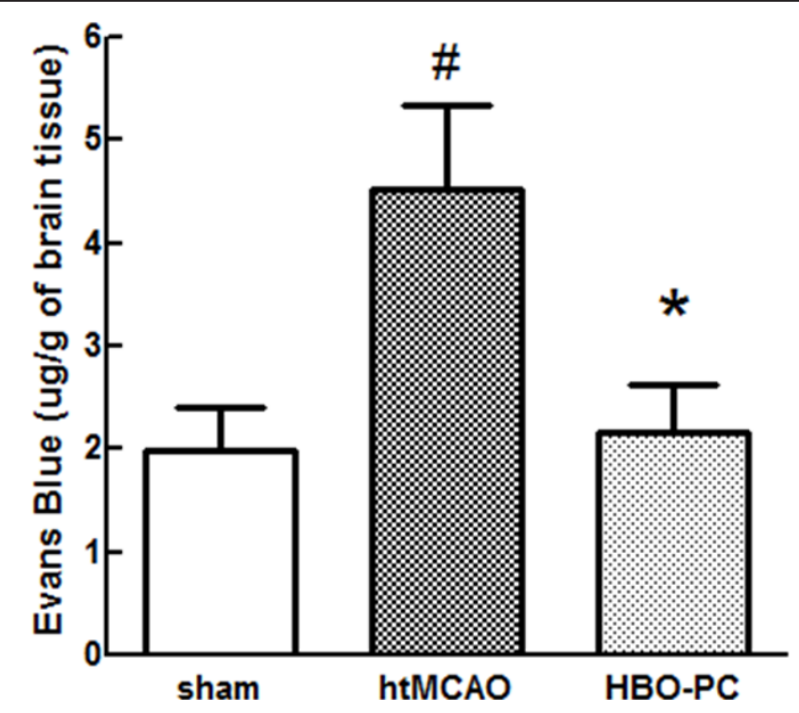

Figure $4 \mathrm{HBO}$ preconditioning significantly reduced Evans blue extravasation. Animals were injected with Evans blue $23 \mathrm{~h}$ after MCAO. At $1 \mathrm{~h}$ after injection, animals were sacrificed after cardiac perfusion and quantitative evaluation analysis was evaluated. Extravasated Evans blue dye was significantly reduced by HBO-PC. *P $>0.05$ vs. htMCAO, ${ }^{\# P}>0.05$ vs. sham.
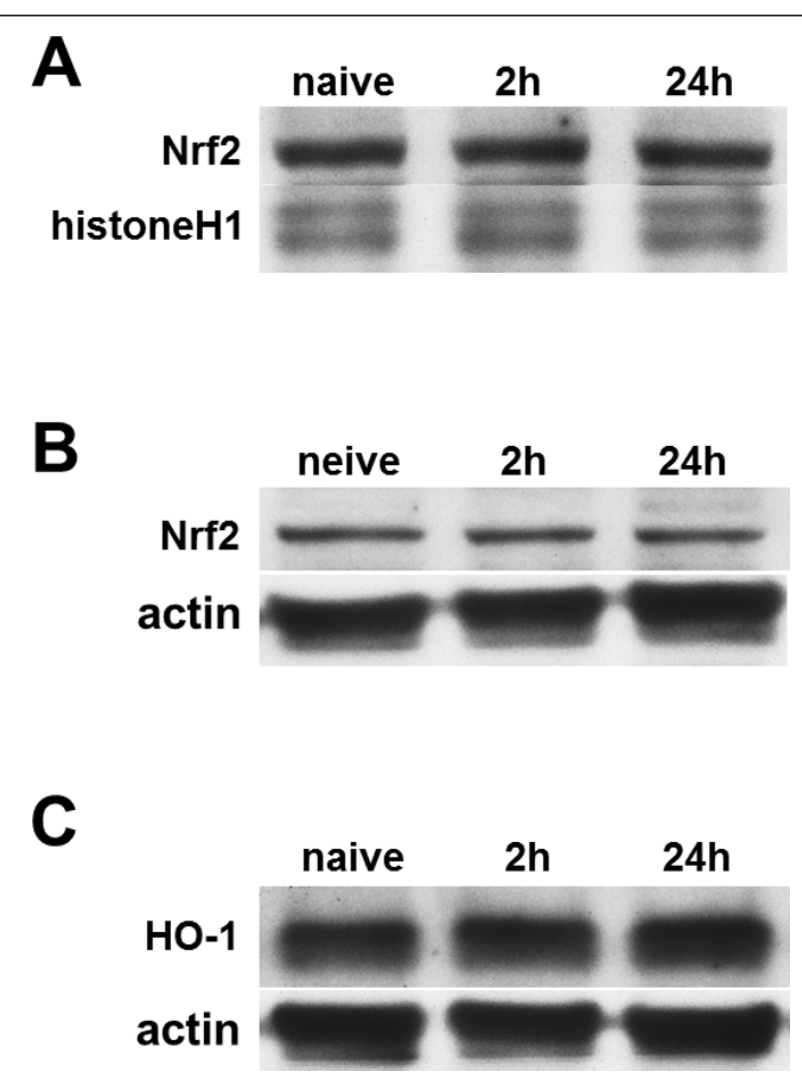

Figure 5 HBO preconditioning had no effect on Nrf2 and HO-1 regulation before tMCAO. Representative immunoblots of Nrf2 in nuclear fraction (A), Nrf2 in cytosolic fraction (B), and $\mathrm{HO}-1$ in cytosolic fraction (C) at different time points after the last session of hyperbaric oxygen therapy. There was no statistically significant difference among each time points following HBO-PC. 

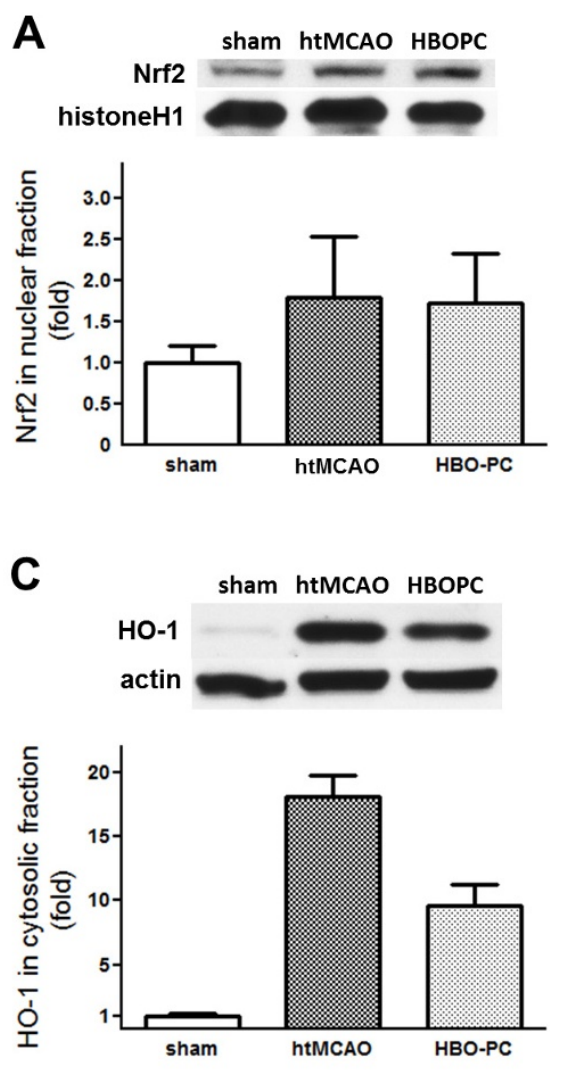
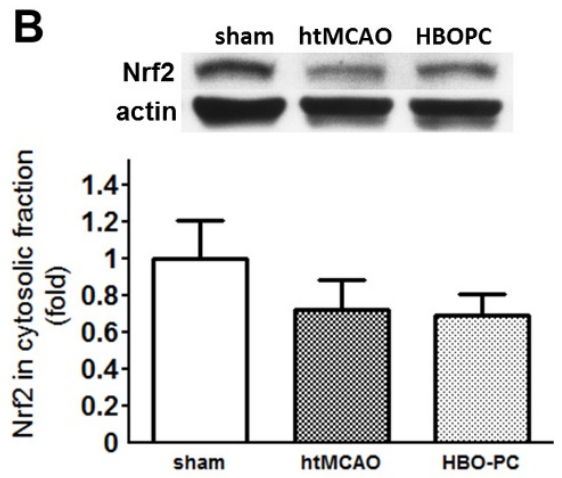

Figure 6 HBO preconditioning had no effect on Nrf2 regulation, and significantly reduced HO-1 expression. Representative immunoblots and densitometric analysis of Nrf2 in nuclear fraction (A), Nrf2 in cytosolic fraction (B), and HO-1 in cytosolic fraction (C) at $24 \mathrm{~h}$ after MCAO. HBO-PC had no effect on Nrf2 regulation. Furthermore, HO-1 was downregulated by HBO-PC. ${ }^{*} P>0.05$ vs. htMCAO, ${ }^{\#} P>0.05$ vs. sham.

Further studies will be needed to explore the mechanism and to define the optimal regimen of HBO-PC.

\section{Authors' contributions}

YS conducted most of the animal surgery and wrote the first draft of this paper. RPO provided guidance for surgery and technical support for morphological studies. AM conducted animal behavioral testing. MF assisted in molecular biological studies. JT provided guidance in molecular biological studies. JHZ provided overall supervision. All authors read and approved the final manuscript.

\section{Competing interests}

The authors declare that they have no competing interests.

Received: 18 January 2012 Accepted: 11 April 2012

Published: 11 April 2012

\section{References}

1. Capes SE, Hunt D, Malmberg K, Pathak P, Gerstein HC: Stress hyperglycemia and prognosis of stroke in nondiabetic and diabetic patients: a systematic overview. Stroke 2001, 32:2426-2432.

2. Garg R, Chaudhuri A, Munschauer F, Dandona P: Hyperglycemia, insulin, and acute ischemic stroke: a mechanistic justification for a trial of insulin infusion therapy. Stroke 2006, 37:267-273.

3. Witt KA, Mark KS, Hom S, Davis TP: Effects of hypoxia-reoxygenation on rat blood-brain barrier permeability and tight junctional protein expression. Am J Physiol Heart Circ Physiol 2003, 285:H2820-H2831.
4. Krizbai IA, Bauer H, Bresgen N, Eckl PM, Farkas A, Szatma'ri E, Traweger A, Wejksza K, Bauer H-C: Effect of oxidative stress on the junctional proteins of cultured cerebral endothelial cells. Cell Mol Neurobiol 2005, 25:129-139.

5. Ishii T, Itoh K, Takahashi S, Sato H, Yanagawa T, Katoh Y, Bannai S, Yamamoto M: Transcription factor Nrf2 coordinately regulates a group of oxidative stress-inducible genes in macrophages. J Biol Chem 2000, 275:16023-16029.

6. Shih AY, Johnson DA, Wong G, Kraft AD, Jiang L, Erb H, Johnson JA, Murphy TH: Coordinate regulation of glutathione biosynthesis and release by Nrf2-expressing glia potently protects neurons from oxidative stress. J Neurosci 2003, 23:3394-3406.

7. Satoh T, Okamoto SI, Cui J, Watanabe Y, Furuta K, Suzuki M, Tohyama K, Lipton SA: Activation of the Keap1/Nrf2 pathway for neuroprotection by electrophillic phase II inducers. Proc Natl Acad Sci 2000, 103:768-773.

8. Lee JM, Calkins MJ, Chan K, Kan YW, Johnson JA: Identification of the NFE2-related factor-2-dependent genes conferring protection against oxidative stress in primary cortical astrocytes using oligonucleotide microarray analysis. J Biol Chem 2003, 278:12029-12038.

9. Tenhunen R, Marver HS, Schmid R: The enzymatic conversion of heme to bilirubin bymicrosomal heme oxygenase. Proc Natl Acad Sci 1968, 61:748-755.

10. Wada K, Miyazawa T, Nomura N: Preferential conditions for and possible mechanisms of induction of ischemic tolerance by repeated hyperbaric oxygenation in gerbil hippocampus. Neurosurgery 2001, 49:160-166, discussion 166-167.

11. Dong $H$, Xiong $L$, Zhu Z: Preconditioning with hyperbaric oxygen and hyperoxia induces tolerance against spinal cord ischemia in rabbits. Anesthesiology 2002, 96:907-912. 
12. Kim CH, Choi H, Chun YS: Hyperbaric oxygenation pretreatment induces catalase and reduces infarct size in ischemic rat myocardium. Pflugers Arch 2001, 442:519-525.

13. Chaves JC, Fagundes DJ, Simoes Mde J: Hyperbaric oxygen therapy protects the liver from apoptosis caused by ischemia-reperfusion injury in rats. Microsurgery 2009, 29:578-583.

14. Godman CA, Chheda KP, Hightower LE, Perdrizet G, Shin DG, Giardina C: Hyperbaric oxygen induces a cytoprotective and angiogenic response in human microvascular endothelial cells. Cell Stress Chaperones 2010, 15:431-442.

15. Hu Q, Chen C, Yan J, Yang X, Shi X, Zhao J, Lei J, Yang L, Wang K, Chen L, Huang $\mathrm{H}$, Han J, Zhang JH, Zhou C: Therapeutic application of gene silencing MMP-9 in a middle cerebral artery occlusion-induced focal ischemia rat model. Exp Neurol 2009, 216:35-46.

16. Swanson RA, Sharp FR: Infarct measurement methodology. I Cereb Blood Flow Metab 1994, 14:697-698

17. Choudhri TF, Hoh BL, Solomon RA, Connolly ES Jr, Pinsky DJ: Use of a spectrophotometric hemoglobin assay to objectively quantify intracerebral hemorrhage in mice. Stroke 1997, 28:2296-2302.

18. Belayev L, Ginsberg MD, Alonso OF, Singer JT, Zhao W, Busto R: Bilateral ischemic tolerance of rat hippocampus induced by prior unilateral transient focal ischemia: relationship to $c$-fos mRNA expression. Neuroreport 1996, 8:55-59.

19. Garcia JH, Wagner S, Liu KF, Hu XJ: Neurological deficit and extent of neuronal necrosis attributable to middle cerebral artery occlusion in rats. Statistical validation. Stroke 1995, 26:627-634, discussion 635.

20. Hu Q, Ma Q, Zhan Y, He Z, Tang J, Zhou C, Zhang J: Isoflurane enhanced hemorrhagic transformation by impairing antioxidant enzymes in hyperglycemic rats with middle cerebral artery occlusion. Stroke 2011 42:1750-1756

21. Kirino T: Ischemic tolerance. J Cereb Blood Flow Metab 2002, 22:1283-1296.

22. Wada K, Ito M, Miyazawa T, Katoh H, Nawashiro H, Shima K, Chigasaki H: Repeated hyperbaric oxygen induces ischemic tolerance on gerbil hippocampus. Brain Res 1996, 720:15-20.

23. Prass K, Wiegand F, Schumann P, Ahrens M, Kapinya K, Harms C, Liao W, Trendelenburg G, Gertz K, Moskowitz MA, Knapp F, Victorov IV, Megow D, Dirnagl U: Hyperbaric oxygenation induced tolerance against focal cerebral ischemia in mice is strain dependent. Brain Res 2000, 871:146-150

24. Huang TY, Tsai PS, Wang TY, Huang CL, Huang CJ: Hyperbaric oxygen attenuation of lipopolysaccharide-induced acute lung injury involves heme oxygenase-1. Acta Anaesthesiol Scand 2005, 49:1293-1301.

25. Liu Y, Sun XJ, Liu J, Kang ZM, Deng XM: Heme oxygenase-1 could mediate the protective effects of hyperbaric oxygen preconditioning against hepatic ischemia-reperfusion injury in rats. Clin Exp Pharmacol Physiol 2011, 38:675-682.

26. He X, Xu X, Fan M, Chen X, Sun X, Luo G, Chen L, Mu Q, Feng Y, Mao Q, Chao Z: Preconditioning with hyperbaric oxygen induces tolerance against renal ischemia-reperfusion injury via increased expression of heme oxygenase-1. J Surg Res 2011, 170:271-277.

27. Benedetti S, Lamorgese A, Piersantelli M, Pagliarani S, Benvenuti F, Canestrari F: Oxidative stress and antioxidant status in patients undergoing prolonged exposure to hyperbaric oxygen. Clin Biochem 2004, 37:312-317.

28. Yu SY, Chiu JH, Yang SD, Yu HY, Hsieh CC, Chen PJ, Lui WY, Wu CW: Preconditioned hyperbaric oxygenation protects the liver against ischemia-reperfusion injury in rats. J Surg Res 2005, 128:28-36.

29. Cherubini A, Ruggiero C, Polidori MC, Mecocci P: Potential markers of oxidative stress in stroke. Free Radic Biol Med 2005, 39:841-852.

30. Ostrowski RP, Jadhav V, Chen W, Zhang JH: Reduced matrix metalloproteinase-9 activity and cell death after global ischemia in the brain preconditioned with hyperbaric oxygen. Acta Neurochir Suppl 2010, 106:47-49.

31. Hu SL, Hu R, Li F, Liu Z, Xia YZ, Cui GY, Feng H: Hyperbaric oxygen preconditioning protects against traumatic brain injury at high altitude. Acta Neurochir Suppl 2008, 105:191-196.

32. Siesjö BK, Katsura Kl, Kristián T, Li PA, Siesjö P: Molecular mechanisms of acidosis-mediated damage. Acta Neurochir Suppl 1996, 66:8-14. doi:10.1186/2045-9912-2-9

Cite this article as: Soejima et al:: Hyperbaric oxygen preconditioning attenuates hyperglycemia enhanced hemorrhagic transformation after transient MCAO in rats. Medical Gas Research 2012 2:9.

\section{Submit your next manuscript to BioMed Central and take full advantage of:}

- Convenient online submission

- Thorough peer review

- No space constraints or color figure charges

- Immediate publication on acceptance

- Inclusion in PubMed, CAS, Scopus and Google Scholar

- Research which is freely available for redistribution

Submit your manuscript at www.biomedcentral.com/submit
C Biomed Central 